OPEN ACCESS

Edited by:

Argye Hillis,

Johns Hopkins Medicine,

United States

Reviewed by:

Fiona Kumfor,

University of Sydney, Australia

Charalambos Themistocleous,

Johns Hopkins Medicine

United States

${ }^{*}$ Correspondence:

Diana Van Lancker Sidtis diana.sidtis@nyu.edu

Specialty section

This article was submitted to Applied Neuroimaging, a section of the journal Frontiers in Neurology

Received: 06 April 2018

Accepted: 25 June 2018

Published: 24 July 2018

Citation:

Sidtis DVL and Sidtis JJ (2018) The

Affective Nature of Formulaic

Language: A Right-Hemisphere Subcortical Process.

Front. Neurol. 9:573.

doi: 10.3389/fneur.2018.00573

\section{The Affective Nature of Formulaic Language: A Right-Hemisphere Subcortical Process}

\author{
Diana Van Lancker Sidtis* and John J. Sidtis \\ Communicative Sciences and Disorders, New York University, New York, NY, United States
}

Formulaic expressions naturally convey affective content. The unique formal and functional characteristics of idioms, slang, expletives, proverbs, conversational speech formulas, and the many other conventional expressions in this repertory have been well-described: these include unitary form, conventionalized and non-literal meanings, and reliance on social context. Less highlighted, but potent, is the intrinsic presence of affective meaning. Expletives, for example, signal strong emotion. Idioms, too, inherently communicate emotional connotations, and conversational speech formulas allow for empathetic bonding and humor. The built-in affective content of formulaic expressions, in combination with their other unique characteristics, is compatible with the proposal that brain structures other than those representing grammatical language are in play in producing formulaic expressions. Evidence is presented for a dual process model of language, whereby a right hemisphere-subcortical system modulates formulaic language.

Keywords: formulaic language, (LH) damage, PET, RH damage, neurolinguistic

Connotations, affect, attitudes, and emotional meanings inhere essentially in formulaic language-fixed, unitary expressions that are known to a language community. Expletives (Dammit, Good heavens) make this point easily: their purpose is to communicate anger, surprise, shock, disapproval, or excitement (1-4). Idioms engage emotional arousal, subtle or strong, positive or negative. The idiom he's out on a limb communicates worry, risk, failure, and anxiety, while a matched literal sentence, he's out in a boat, is neutral. Don't bite the hand that feeds you carries a warning and a criticism; He pulled the rug out from under us implies disappointment, dismay, and reproachful anger. As a standard ingredient of their meaning-e.g., Sleep with one eye open, In a nutshell, He's at the end of his rope, Just in the nick of time, Quit cold turkey, Shoot for the stars, You lucky dog, You're playing with fire, She has a snowball's chance in hell, I'll be there with bells on-formulaic expressions weave together affect and attitude, which may be empathetic, reproachful, suspicious, or encouraging. Similarly, conversational speech formulas (Okay!, Right!, Really? You're kidding!, Gotcha!; Whatever!; Go to hell; Knock on wood; It's all good; Shut your cakehole!) carry connotations of affirmation or rejection, assent or disapproval, cooperativeness or resistance, through their bonding and affiliative functions (5-7). Routinized speech formulas form a large part of daily talk, communicating "beliefs, wants, wishes, preferences, norms, and values." [(8), p. 239]. 


\section{NEUROLINGUISTIC BACKGROUND}

The early impetus for recognizing the role of formulaic expressions (FEs) in speaking arose from observations in aphasia, using the term "automatic speech." Starting with J. Hughlings Jackson in the nineteenth century $(9,10)$, clinicians with exposure to aphasia noted that fixed, holistic, known utterances are well-preserved despite severe language impairment [e.g., (1117)]; these clinical observations were confirmed by systematic surveys (18-21). Early categories of "automatic" serial speech (counting and days of the week) have been greatly expanded to cover a very large domain. FEs are utilized to communicate in aphasic speech (22) and they play a key role in rehabilitation (23-25).

Examination of monologs from persons with left hemisphere (LH) damage and aphasia reveal high proportions of FEs, while right hemisphere $(\mathrm{RH})$ damage is associated with significantly lower proportions $(26,27)$. Baldo et al. (28) also reported a trend toward fewer FEs in elicited responses in $\mathrm{RH}$ damaged speech than healthy speakers. Formal testing of persons with aphasia supported a preserved ability for FEs (29-31).

Persons with Alzheimer's disease (AD) speak with a preponderance of FEs throughout the progression of the disease; $\mathrm{AD}$ leaves the basal ganglia essentially intact for a considerable time (32). In contrast, Parkinsonian disease (PD) arises from impaired subcortical motor nuclei. Experimental studies confirmed that $\mathrm{AD}$ speakers proportions of FEs are higher than healthy speakers, while PD speakers show deficient output (33-36).

\section{FUNCTIONAL IMAGING AND THE DUAL PROCESS MODEL OF LANGUAGE}

The few functional imaging studies dealing with FEs have yielded contradictory results (This review focuses on production and does not include studies of novel metaphor). Using a precursor $\left({ }^{133} \mathrm{Xe}\right)$ of PET, Larsen et al. (37) studied subjects at rest or while

\section{Phonological/Lexical Production Rate}
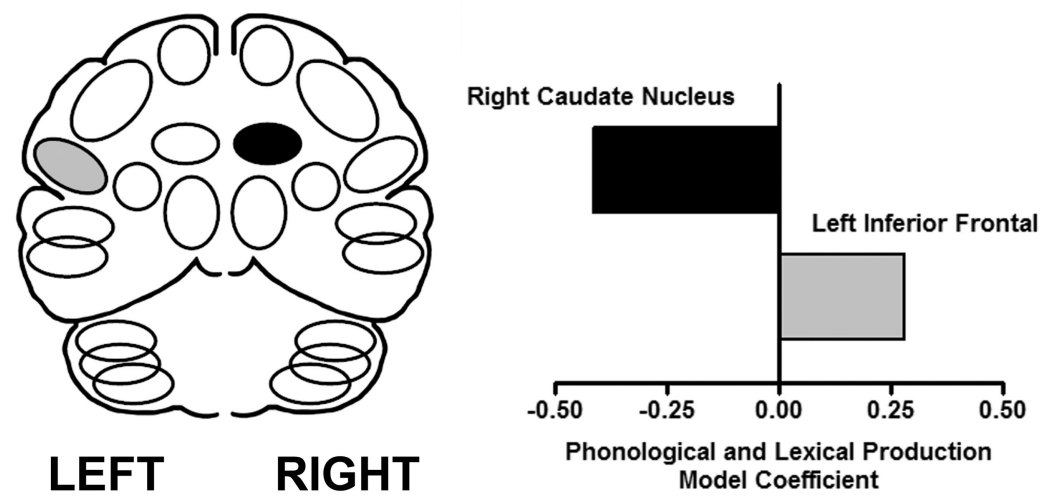

\section{Proportion of Words in FEs}
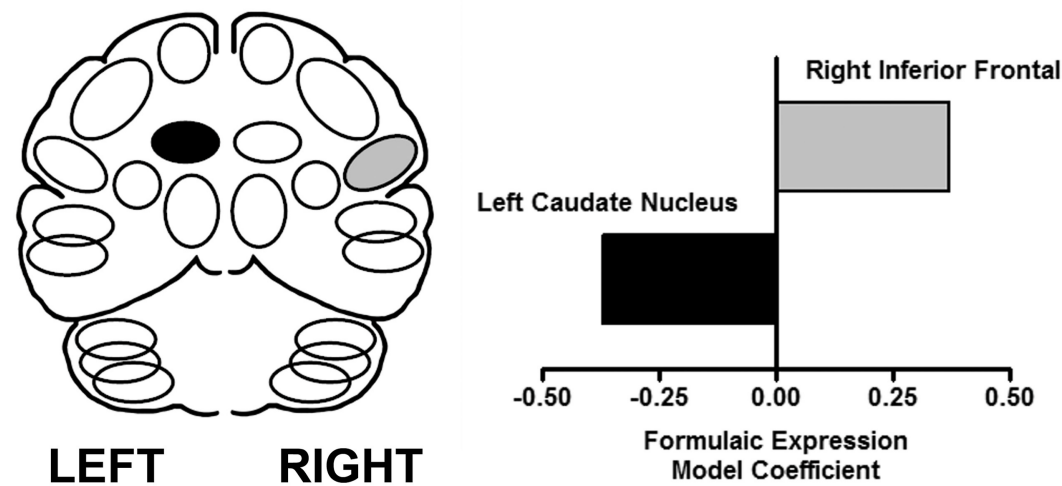

FIGURE 1 | The results of performance-based analyses identifying relationships between brain regions that predict syllable and word production rate (top), and the proportion of words in FEs (bottom) using a multiple linear regression analysis. The X axis represents the multiple linear regression weights obtained in this analysis. On the left are schematic views of the predictor regions (light fill is an increase, dark fill is a decrease). On the right are graphical representations of the regression weights for the brain regions predictive of the respective expressive language measures in the linear regression model (47). 
counting or reciting the weekdays. Rest values were subtracted from speaking values. For subjects who had the LH studied, there were significant task differences in two of four frontal regions. For subjects whose RH was studied, there were no differences in these regions. Interpretations were problematic because no direct leftright comparisons were possible, the normalization was different for left and right data sets, and task subtraction was employed.

Bookheimer et al. (38) used oxygen-labeled water with PET to study serial-months and the Pledge of Allegiance. Syllable repetition and an oral-motor task were included with a resting state. Using subtraction, the data from the non-propositional tasks were contrasted with data from the rest state. Of the 24 brain regions with blood flow increases, 14 were in the $\mathrm{LH}$ while 10 were in the RH. The results regarding functional lateralization were thus not definitive.

Using PET, counting and recitation of nursery rhymes were contrasted with spontaneous monologs (39). All tasks resulted in activation of left hemisphere frontal and temporal sites. This study relied on multiple, complex and simple additions and subtractions of images, lending complexity to interpretation.

Finally, in another PET study, healthy subjects produced animal names, vocalized syllables, and counting. Instead of subtraction, a partial least squares analysis was used (40). Three significant latent variables were identified: one for naming and syllables, with left anterior area predominating over right; a second for naming in bilateral anterior areas, and a third, associated with counting, involved $\mathrm{RH}$ and subcortical sites (41). Unlike the previous studies reviewed, these results corresponded to clinical observations, whereby even the most severely aphasic individuals can count.

We report a PET imaging study examining FEs, recently performed in our laboratory, using a complementary approach to activation methods: performance-based analysis. This method explores factors that contribute to cerebral lateralization for language $(42,43)$. The approach determines if there is a linear combination of brain regions that is predictive of performance during scanning. It is a fundamentally different approach to brain-behavior relationships as it does not rely on group mean differences or task contrasts. Rather, it identifies relationships between individual differences in performance and individual differences in brain activity. This method has consistently yielded functional profiles that are compatible with clinical observations (44).

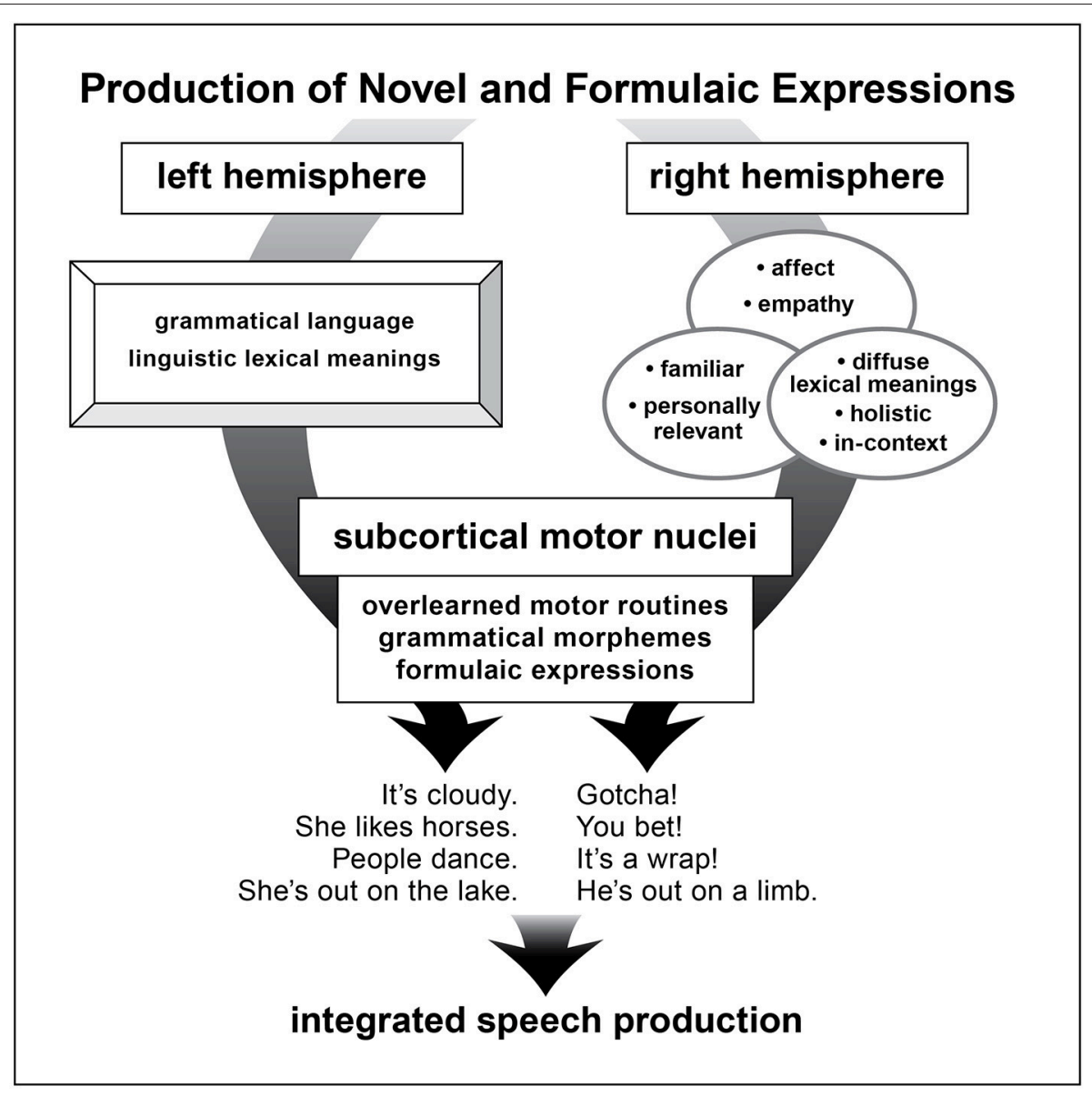

FIGURE 2 | A schematic depiction of brain structures underlying production of novel and formulaic utterances as proposed in the dual process mocel of language. 
Speech samples (monologs, syllables and words) produced during scanning were recorded for acoustic and linguistic analyses. From monologs, FEs were quantified as the proportion of FE words in the total word count. Based on previous studies $(45,46)$, multiple regions were measured for the inferior frontal area and the caudate, bilaterally. The results are presented in Figure 1. Using a multiple linear regression analysis, the predictors of speech rate showed that as syllable and word production rates increased, blood flow increased in the left inferior frontal region and decreased in the right caudate. In contrast, the predictive model for the proportion of FEs in the monologs was a complementary pattern of cortical-subcortical interaction. As the proportion of FEs in the monologs increased, blood flow increased in the right inferior frontal region and decreased in the left caudate (47). This laterality profile is consistent with the effects of RH damage on the expression of FEs.

\section{DISCUSSION}

Formulaic expressions naturally carry an affective load. Idioms, proverbs, and other conventional expressions communicate a large range of positive and negative affects, implied within their non-literal meaning. In studies of persons with unilateral lesions and progressive neurological disease, it was observed that formulaic language relies on a cooperation between the cortical $\mathrm{RH}$ and subcortical nuclei. Performance based analysis of cerebral blood flow measured during formulaic and propositional speech identified predictive, complementary patterns corresponding with these two modes. Greater use of conversational speech formulas was associated with increased blood flow in the $\mathrm{RH}$ and reduced flow in the left caudate. Exemplars of propositional speech were significantly associated with the opposite pattern.

Known characteristics of the brain systems modulating formulaic as contrasted with grammatical language are compatible with the proposed dual model of language [e.g., (4851)]. The RH specializes $(52,53)$ in empathy (including "theory of mind”) (54-59), affect and emotional experiencing (60-62), social-context based meanings and pragmatic competence

\section{REFERENCES}

1. Hughes G. Swearing: A Social History of Foul Language, Oaths, and Profanity in English. Oxford: Blackwell (1991).

2. Jay TB. Why We Curse: A Neuro-Psycho-Social Theory of Speech. Amsterdam: John Benjamins Publishing Co. (2000).

3. Montagu A. The Anatomy of Swearing. London: Rapp and Whiting (1967).

4. Van Lancker D, Cummings J. Expletives: neurolinguistic and neurobehavioral perspectives on swearing. Brain Res Rev. (1999) 31:83-104. doi: 10.1016/S0165-0173(99)00060-0

5. Drew P, Holt E. Complainable matters: the use of idiomatic expressions in making complaints. Soc. Probl. (1988) 35:398-417. doi: 10.2307/800594

6. Kecskes I. A cognitive-pragmatic approach to situation-bound utterances. $J$ Pragmat. (2000) 32:605-25. doi: 10.1016/S0378-2166(99)00063-6

7. Wray A, Perkins M. The functions of formulaic language: an integrated model. Lang. Commun. (2000) 20:1-28. doi: 10.1016/S0271-5309(99)00015-4
$(28,63-68)$, diffuse lexical processes (69-71), personal familiarity (72, 73), and holistic configurations (74-76).

The basal ganglia stores and processes overlearned motor gestures. The characteristics of subcortical structures, shown to be important in FE production, include modulating routinized motor and verbal gestures $(77,78)$, including grammatical elements $(79,80)$ and recited speech $(81,82)$. Basal ganglia impairment interferes with normal production of FEs (36).

Both of these structures, $\mathrm{RH}$ and basal ganglia, in their intrinsic functionality are well-suited to the properties of FEs (see Figure 2).

In the dual processing language model, two distinctive modes of language competence exist: formulaic and grammatical (83-87). These language modes have different intrinsic characteristics and rely on disparate cerebral systems. Further studies can look toward uncovering the cerebral switching mechanisms that allow for smooth integration of these two modes in fluent speech. Recognition of the dual process of language competence has important implications for our understanding of first language acquisition, second language learning, and clinical rehabilitation of language disorders.

\section{AUTHOR CONTRIBUTIONS}

DS wrote major portions of paper, partly designed and contributed to experimental study reported in the paper. IS wrote portions of paper, partly designed and contributed to experimental study reported in paper, analyzed functional imaging results.

\section{ACKNOWLEDGMENTS}

This work was supported by the National Institute of Deafness and Communicative Disorders (R01 DC007658). The assistance of Phoebe Spetsieris and the PET imaging team at the Feinstein Institute, and Michele Burgevin, Vanessa Monserrat, and the members of the Brain and Behavior Laboratory and the Discovery Science Project at the Nathan Kline Institute are gratefully appreciated.

8. Coulmas F. On the sociolinguistic relevance of routine formulae.J Pragmat. (1979) 3:239-66. doi: 10.1016/0378-2166(79)90033-X

9. Hughlings Jackson J. On the nature of the duality of the brain. In: Taylor J, editor. Selected Writings of John Hughlings Jackson, Vol. 2, 1932. London: Hodder and Stoughton (1874), p. 129-45.

10. Hughlings Jackson J. H. On affections of speech from disease of the brain. Brain, 1, 304-330; Reprinted In: Taylor J, editor. Selected Writings of John Hughlings Jackson, Vol. 2, 1932. London: Hodder \& Stoughton (1878), p. 155-204. doi: 10.1093/brain/1.3.304

11. Bay E. Principles of classification and their influence on our concepts of aphasia. In: De Reuck AVS, O'Connor M, editors. Disorders of Language. CIBA Foundation Symposium. London: J. and A. Churchill, Ltd (1964).

12. Benson DF. Aphasia, Alexia, and Agraphia. New York, NY: Churchill Livingston (1979).

13. Critchley M. Aphasiology and Other Aspects of Language. London: Edward Arnold (1970). 
14. Espir L, Rose F. The Basic Neurology of Speech. Oxford: Blackwell Scientific Publications (1970).

15. Head H. Aphasia and Kindred Disorders of Speech. Cambridge: The University Press (1926).

16. Luria AR. Higher Cortical Functions in Man. New York, NY: Basic Books (1966).

17. Marie P. A singular trouble with speech: Palilalia (dissociation of voluntary speech and of automatic speech). Le Monde Medical, 664, 329-344; Reprinted In: Cole MF, Cole M, editors. (1971), Pierre Marie's Papers on Speech Disorders. New York, NY: Hafner Publishing Co (1925/71).

18. Blanken G, Wallesch CW, Papagno C. Dissociations of language functions in aphasics with speech automatisms (recurring utterances). Cortex (1990) 26:41-63. doi: 10.1016/S0010-9452(13)80074-3

19. Code C. Neurolinguistic analysis of recurrent utterances in aphasia. Cortex (1982) 18:141-52. doi: 10.1016/S0010-9452(82)80025-7

20. Code C. Language, Aphasia, and the Right Hemisphere. Chichester: John Wiley (1987).

21. Code C. Speech automatism production in aphasia. J Neurolinguist. (1994) 8:135-48. doi: 10.1016/0911-6044(94)90021-3

22. McElduff KM, Drummond SS. Communicative functions of automatic speech in non-fluent dysphasia. Aphasiology (1991) 5:265-78. doi: 10.1080/02687039108248528

23. Stahl B, Henseler I, Turner R, Geyer S, Kotz SA. How to engage the right brain hemisphere in aphasics without even singing: evidence for two paths of speech recovery. Front Hum Neurosci. (2013) 7:35. doi: 10.3389/fnhum.2013.00035

24. Stahl B, Kotz SA, Hensler I, Turner R, Geyer S. Rhythm in disguise: why singing may not hold the key to recovery from aphasia. Brain (2011) 134:3083-93. doi: 10.1093/brain/awr240

25. Stahl B, Van Lancker Sidtis D. Tapping into neural resources of communication: formulaic language in aphasia therapy. Front Psychol. (2015) 6:1526. doi: 10.3389/fpsyg.2015.01526

26. Van Lancker Sidtis D, Postman WA. Formulaic expressions in spontaneous speech of left- and right-hemisphere damaged subjects. Aphasiology (2006) 20:411-26. doi: 10.1080/02687030500538148

27. Yang S-Y, Van Lancker Sidtis D. Production of Korean idiomatic utterances following left- and right-hemisphere damage: acoustic studies. J Speech Lang Hear Res. (2016) 59:267-80. doi: 10.1044/2015_JSLHR-L-15-0109

28. Baldo JV, Kacinik NA, Moncrief A, Beghin F, Dronkers NF. You may now kiss the bride: Interpretation of social situations by individuals with right or left hemisphere injury. Neuropsychologia (2016) 80:133-41. doi: 10.1016/j.neuropsychologia.2015.11.001

29. Lum C, Ellis AW. Is "nonpropositional" speech preserved in aphasia? Brain Lang. (1994) 46:368-91.

30. Lum C, Ellis AW. Why do some aphasics show an advantage on some tests of nonpropositional (automatic) speech? Brain Lang. (1999) 70:95-118. doi: 10.1006/brln.1999.2147

31. Van Lancker Sidtis D, Yang S-Y. Formulaic language performance in left- and right-hemisphere damaged patients: structured testing. Aphasiology (2016) 31:82-99. doi: 10.1080/02687038.2016.1157136

32. Cummings JL. Clinical Neuropsychiatry. Orlando, FL: Grune and Stratton (1985).

33. Bridges K, Van Lancker Sidtis D. Formulaic language in Alzheimer's disease. Aphasiology (2013) 27:799-810. doi: 10.1080/02687038.2012.757760

34. Illes J. Neurolinguistic features of spontaneous language production dissociate three forms of neurodegenerative disease: Alzheimer's, Huntington's, and Parkinson's. Brain Lang. (1989) 37:628-42.

35. Speedie LJ, Wertman E, T'air J, Heilman KM. Disruption of automatic speech following a right basal ganglia lesion. Neurology (1993) 43:1768-74.

36. Van Lancker Sidtis D, Choi J-H, Alken A, Sidtis JJ. Formulaic language in Parkinson's and Alzheimer's disease: complementary effects of subcortical and cortical dysfunction. J Speech Lang Hear Res. (2016) 58:1493-507. doi: 10.1044/2015_JSLHR-L-14-0341

37. Larsen B, Skinhoj E, Lassen NA. Variations in regional cortical blood flow in the right and left hemispheres during automatic speech. Brain (1978) 101:193-209. doi: 10.1093/brain/101.2.193

38. Bookheimer SY, Zeffiro TA, Blaxton TA, Gaillard PW, Theodore WH. Activation of language cortex with automatic speech tasks. Neurology (2000) 55:1151-7. doi: 10.1212/WNL.55.8.1151
39. Blank SC, Scott S, Murphy K, Warburton E, Wise R. Speech production: Wernicke, Broca and beyond. Brain (2002) 125:1829-38. doi: 10.1093/brain/awf191

40. McIntosh AR, Bookstein FL, Haxby JV, Grady CL. Spatial pattern analysis of functional brain images using partial least squares. Neuroimage (1996) 3:143-57. doi: 10.1006/nimg.1996.0016

41. Van Lancker D, McIntosh R, Grafton R. PET activation studies comparing two speech tasks widely used in surgical mapping. Brain Lang. (2003) 85:245-61. doi: 10.1016/S0093-934X(02)00596-5

42. Sidtis JJ. Performance-based connectivity analysis: a path to convergence with clinical studies. Neuroimage (2012) 59:2316-21. doi: 10.1016/j.neuroimage.2011.09.037

43. Sidtis JJ. What the speaking brain tells us about functional imaging. In: Faust M, editor. Handbook of the Neuropsychology of Language, Vol. 2. Malden, MA: Wiley-Blackwell (2012). p. 565-618. doi: 10.1002/978111843250 1.ch27

44. Sidtis JJ, Gomez C, Naoum A, Strother SC, Rottenberg DA. Mapping cerebral blood flow during speech production in hereditary ataxia. NeuroImage (2006) 31:246-54. doi: 10.1016/j.neuroimage.2005.12.005

45. Sidtis JJ, Strother SC, Groshong A, Rottenberg DA, Gomez C. Longitudinal cerebral blood flow changes during speech in hereditary ataxia. Brain Lang. (2010) 114:43-51. doi: 10.1016/j.bandl.2010.03.007

46. Sidtis JJ, Strother SC, Rottenberg DA. Predicting performance from functional imaging data: methods matter. Neuroimage (2003) 20:615-24. doi: 10.1016/S1053-8119(03)00349-5

47. Sidtis JJ, Van Lancker Sidtis D, Dhawan V, Eidelberg D. Switching language modes: complementary brain patterns for formulaic and propositional language. Brain Connect. (2018) 8:189-96. doi: 10.1089/brain.201 7.0573

48. Bever TG. Cerebral asymmetries in humans are due to the differentiation of two incompatible processes: holistic and analytic. Ann N Y Acad Sci. (1975) 263:251-62. doi: 10.1111/j.1749-6632.1975.tb41589.x

49. Hellige JB. Hemispheric Asymmetry: What's Right and What's Left. Cambridge, MA: Harvard University Press (1993).

50. Kosslyn SM, Koenig O, Barrett A, Cave CB, Tang J, Gabrieli JDE. Evidence for two types of spatial representations: hemispheric specialization for categorical and coordinate relations. J Exp Psychol Hum Percept Perform. (1989) 15:723-35. doi: 10.1037/0096-1523.15.4.723

51. McGilchrist I. The Master and His Emissary: The Divided Brain and the Making of the Western World. New Haven and London: Yale University Press (2009).

52. Myers P. Profiles of communication deficits in patients with right cerebral hemisphere damage: implications for diagnosis and treatment. Aphasiology (2005) 19:1147-60. doi: 10.1080/02687030500331585

53. Van Lancker D. Rags to riches: our increasing appreciation of cognitive and communicative abilities of the human right cerebral hemisphere. Brain Lang. (1997) 57:1-11. doi: 10.1006/brln.1997.1850

54. Champagne-Lavau M, Joanette Y. Pragmatics, theory of mind and executive functions after a right-hemisphere lesion: different patterns of deficits. $J$ Neurolinguist. (2009) 22:413-26. doi: 10.1016/j.jneuroling.2009.02.002

55. Griffin R, Friedman O, Ween J, Winner E, Happé F, Brownell H. Theory of mind and the right cerebral hemisphere: refining the scope of impairment. Laterality (2006) 11:195-225. doi: 10.1080/13576500500450552

56. Leigh R, Oishi K, Hsu H, Lindquist M, Gottesman RF, Jarso S, et al. Acute lesions that impair affective empathy. Brain (2013) 136:2539-49. doi: 10.1093/brain/awt177

57. Shamay-Tsoory SG, Tomer R, Berger BD, Aharon-Peretz J. Characterization of empathy deficits following prefrontal brain damage: the role of the right ventromedial prefrontal cortex. J Cogn Neurosci. (2003) 15:324-37. doi: 10.1162/089892903321593063

58. Siegal M, Carrington J, Radel M. Theory of mind and pragmatic understanding following right hemisphere damage. Brain Lang. (1996) 53:40-50. doi: 10.1006/brln.1996.0035

59. Weed E. Theory of mind impairment in right hemisphere damage: a review of the evidence. Int J Speech Lang Pathol. (2008) 10:414-24. doi: 10.1080/17549500802455429

60. Borod JC, Obler LK, Erhan HM, Grunwald IS, Cicero BA, Welkowitz J, et al. Right hemisphere emotional perception: evidence across multiple channels. Neuropsychology (1998) 12:446-8. doi: 10.1037/0894-4105.12.3.446 
61. Sperry RW, Zaidel E, Zaidel D. Self recognition and social awareness in the deconnected minor hemisphere. Neuropsychologia (1979) 17:153-66. doi: 10.1016/0028-3932(79)90006-X

62. Spence S, Shapiro D, Zaidel E. The role of the right hemisphere in the physiological and cognitive components of emotional processing. Psychophysiology (1996) 33:112-22. doi: 10.1111/j.1469-8986.1996.tb02115.x

63. Cheang HS, Pell MD. A study of humour and communicative intention following right hemisphere stroke. Clin Linguist Phon. (2006) 20:447-62. doi: 10.1080/02699200500135684

64. Cutica I, Bucciarelli M, Bara BG. Neuropragmatics: extralinguistic pragmatic ability is better preserved in left-hemisphere-damaged patients than in right-hemisphere-damaged patients. Brain Lang. (2006) 98:12-25. doi: 10.1016/j.bandl.2006.01.001

65. Fournier NM, Calverley KL, Wagner JP, Poock JL, Crossley M. Impaired social cognition 30 years after hemispherectomy for intractable epilepsy: the importance of the right hemisphere in complex social functioning. Epilepsy Behav. (2008) 12:460-71. doi: 10.1016/j.yebeh.2007.12.009

66. Joanette Y, Goulet $\mathrm{P}$, Hannequin D. Right Hemisphere and Verbal Communication. New York, NY: Springer-Verlag (1990). doi: 10.1007/978-1-4612-4460-8

67. Kaplan JA, Brownell HH, Jacobs JR, Gardner H. The effects of right hemisphere damage on the pragmatic interpretation of conversational remarks. Brain Lang. (1990) 38:315-33. doi: 10.1016/0093-934X(90)90 $117-\mathrm{Y}$

68. Titone DA. Hemispheric differences in context sensitivity during lexical ambiguity resolution. Brain Lang. (1998) 65:361-94.92. doi: 10.1006/brln.1998.1998

69. Grindrod CM. Effects of left and right hemisphere damage on sensitivity to global context during lexical ambiguity resolution. Aphasiology (2012) 26:933-52. doi: 10.1080/02687038.2012.662589

70. Drews E. Quantitatively different organization structure of lexical knowledge in the left and right hemisphere. Neuropsychologia (1987) 25:419-27. doi: 10.1016/0028-3932(87)90029-7

71. Sidtis JJ, Volpe BT, Holtzman JD, Wilson DH, Gazzaniga MS. Cognitive interaction after staged callosal section: evidence for transfer of semantic activation. Science (1981) 212:344-6. doi: 10.1126/science.6782673

72. Cutting J. The Right Hemisphere and Psychiatric Disorders. New York, NY: Oxford (1990).

73. Van Lancker D. Personal relevance and the human right hemisphere. Brain Cogn. (1991) 17:64-92. doi: 10.1016/0278-2626(91)90067-I

74. Brownell H. Surprise but not coherence: sensitivity to verbal humor in right-hemisphere patients. Brain Lang. (1983) 18:20-7. doi: 10.1016/0093-934X(83)90002-0

75. McDonald S. Exploring the cognitive basis of right-hemisphere pragmatic language disorders. Brain Lang. (2000) 75:82-107. doi: $10.1006 /$ brln.2000.2342

76. Van Kleeck MH. Hemispheric differences in global versus local processing of hierarchical visual stimuli by normal subjects: new data and a metaanalysis of previous data. Neuropsychologia (1989) 27:1165-78. doi: 10.1016/0028-3932(89)90099-7

77. Knowlton BJ, Mangels JA, Squire LR. A neostriatal habit learning system in humans. Science (1996) 273:1399-402. doi: 10.1126/science.273.5280.1399

78. Ullman MT. Contributions of memory circuits to language: the declarative-procedural model. Cognition (2004) 92:231-70. doi: 10.1016/j.cognition.2003.10.008

79. Lieberman P, Friedman J, Feldman LS. Syntax comprehension deficits in Parkinson's disease. J Nerv Ment Dis. (1990) 178:360-5.

80. Zanini S, Tavano A, Vorano L, Schiavo F, Gigli GL, Aglioti SM, et al. Greater syntactic impairments in native language in bilingual Parkinsonian patients. J Neurol Neurosurg Psychiatry (2004) 75:1678-81. doi: 10.1136/jnnp.2003.018507

81. Bridges K, Van Lancker Sidtis D, Sidtis JJ. The role of subcortical structures in recited speech: studies in Parkinson's disease. J Neurolinguist. (2013) 26:591-601. doi: 10.1016/j.jneuroling.2013.04.001

82. Shinoura N, Onodera T, Kurokawa K, Tsukada M, Yamada R, Tabei Y, et al. Damage of left temporal lobe resulting in conversion of speech to Sutra, a Buddhist prayer stored in the right hemisphere. Neurocase Neural Basis Cogn. (2010) 16:317-20. doi: 10.1080/13554790903559689

83. Erman B, Warren B. The idiom principle and the open choice principle. Text Int J Study Dis. (2000) 20:29-62. doi: 10.1515/text.1.2000.20.1.29

84. Heine B, Kuteva T, Kalterböck G. Discourse, grammar, the dual process model, and brain lateralization: some correlations. Lang Cogn. (2014) 6:146-80. doi: 10.1017/langcog.2013.3

85. Heine B. On the dualistic nature of discourse processing: linguistic and neurolinguistics observations. In: International Workshop One Brain-Two Grammars? Examining Dualistic Approaches to Grammar and Cognition. Rostok, Germany, March 1-3 (2018).

86. Nespoulous J-L, Code C, Virbel J, Lecours AR. Hypotheses in the dissociation between 'referential' and 'modalizing' verbal behavior in aphasia. Appl Psycholinguist. (1998) 19:311-31.

87. Van Lancker Sidtis D. Formulaic language in an emergentist framework. In: MacWhinney M, O'Grady W, editors. Handbook of Language Emergence, Hoboken, NJ: Wiley-Blackwell (2015). p. 578-99.

Conflict of Interest Statement: The authors declare that the research was conducted in the absence of any commercial or financial relationships that could be construed as a potential conflict of interest.

The reviewer CT and handling Editor declared their shared affiliation.

Copyright (c) 2018 Sidtis and Sidtis. This is an open-access article distributed under the terms of the Creative Commons Attribution License (CC BY). The use, distribution or reproduction in other forums is permitted, provided the original author(s) and the copyright owner(s) are credited and that the original publication in this journal is cited, in accordance with accepted academic practice. No use, distribution or reproduction is permitted which does not comply with these terms. 